\title{
Introduction to wind energy systems
}

\author{
H.-J. WAGNER \\ Ruhr-University Bochum, Energy Systems and Energy Economics \\ P.O. Box 102148, 44721, Bochum, Germany
}

\begin{abstract}
Summary. - This article presents the basic concepts of wind energy and deals with the physics and mechanics of operation. It describes the conversion of wind energy into rotation of turbine, and the critical parameters governing the efficiency of this conversion. After that it presents an overview of various parts and components of windmills. The connection to the electrical grid, the world status of wind energy use for electricity production, the cost situation and research and development needs are further aspects which will be considered.
\end{abstract}

\section{1. - Different wind turbine types: An overview}

Today there are various types of wind turbines in operation, (fig. 1 gives an overview). The most common device is the horizontal-axis wind turbine. This turbine consists of only a few aerodynamically optimised rotor blades, which for the purpose of regulation usually can be tumbled about their long axis (Pitch-regulation). Another cheaper way to regulate it, consists in designing the blades in such a way that the air streaming along the blades will go into turbulence at a certain speed (Stall-Regulation). These turbines can deliver power ranging from $10 \mathrm{~kW}$ to some MW. The largest turbine on the European 


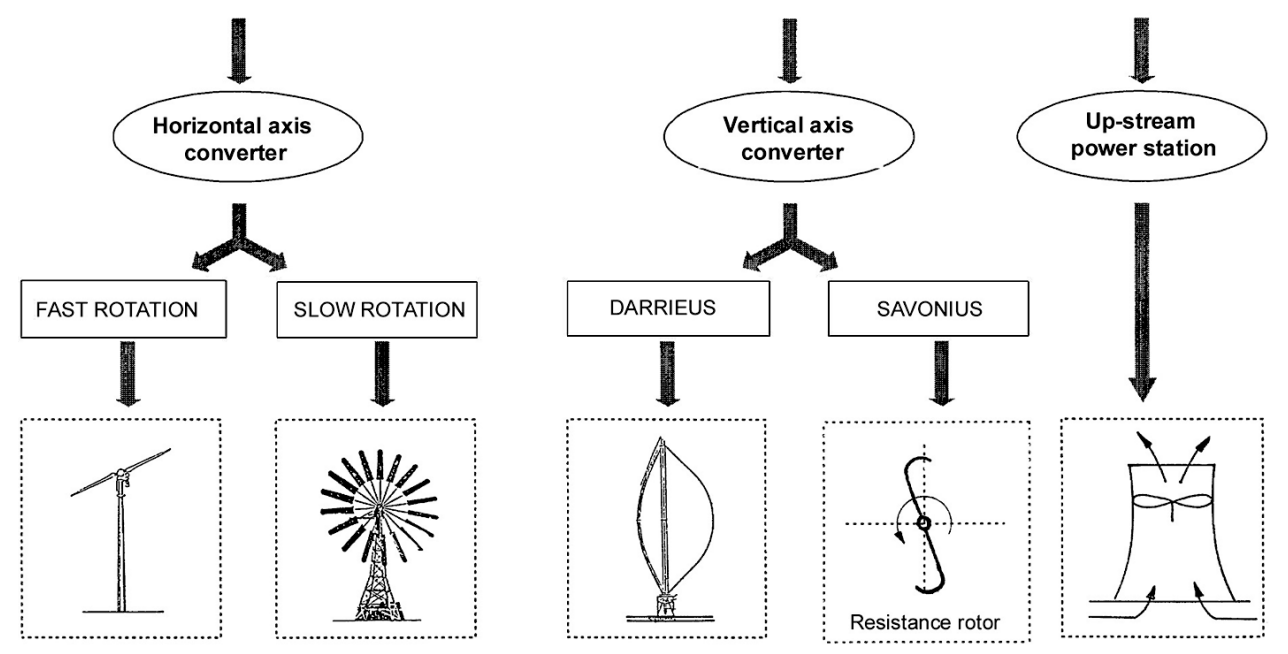

Fig. 1. - Overview of the different types of wind turbines.

market has a power of $8 \mathrm{MW}$, bigger machines are being tested. The efficiency of this type of turbine is very high. Therefore, it is solely used for electricity generation which needs "high-speed engines" to keep the gear transmission and the generator small and cheap.

Another conventional (older) type of horizontal-axis rotor, is the multiblade wind turbine. It was first built about one hundred years ago. Such wind mills have a high starting torque which makes them suitable for driving mechanical water pumps. The number of rotations is low, and the blades are made from simple sheets with an easy geometry. For pumping water, a rotation regulating system is not necessary, but there is a mechanical safety system installed to protect the turbine against storm damage. By using a so-called wind-sheet in lee direction the rotor is turned in the direction of the wind. In order to increase the number of rotations, this type of turbine had been equipped with aerodynamically more efficient blades facilitating the production of electricity, here the area of a blade is smaller.

The mechanical stability of such "slow-speed turbines" is very high, some have had operation periods of more than fifty years.

A third type of turbine is known as DARRIEUS - a vertical-axis construction. Their advantage is that they do not depend on the direction of the wind. To start, they need the help of a generator working as motor or the help of an SAVONIUS rotor installed on top of the vertical axis. In the nineteen eighties a reasonable number of DARRIEUS-turbines had been installed in California, but a further expansion into the higher-power range and in the European markets has not taken place. One reason may be that they are noisier than horizontal-axis turbines. Another disadvantage is that wind velocity increases significantly with height, making horizontal-axis wheels on towers more economical. Nevertheless, there are some companies producing DARRIEUS-turbines in 
the very low power range of a few kilowatts for decentralised electricity supply in areas without electrical grids e.g. in rural areas of developing countries.

The Savonius rotor is only used for research activities, e.g. as a measurement device especially for wind velocity, it is not used for power production. Therefore it will not be discussed in detail in this paper.

The last technique to be dealt with is known as Up-Stream-Power-Station or thermal tower. In principle, it can be regarded as a mix between a wind turbine and a solar collector. In the top of a narrow, high tower is a wind wheel on a vertical axis driven by the rising warm air. A solar collector installed around the foot of the tower heats up the air. The design of the collector is simple; a transparent plastic foil is fixed over several metres on the ground in a circle around the tower. Therefore, the station needs a lot of space and the tower has to be very high. Such a system has a very poor efficiency, only about one percent. World wide there has only been one Up-Stream-Power- Station built so far, it was designed by a German company. For some years it worked satisfactorily at the location of Manzarenas in Spain, but in the mid eighties it was destroyed by bad weather. This station had an electrical power of $20 \mathrm{~kW}$, the tower was about $200 \mathrm{~m}$ high, and the collector had a diameter of approximately the same size. A second Up-StreamPower- Station with an electrical performance of $200 \mathrm{MW}$ was planned in Australia, but not yet realised until. The tower height should be about $1000 \mathrm{~m}$ and the diameter of the collector area should be about $7000 \mathrm{~m}$. There has no new Up-Stream-Power-Station been designed and installed so far. Since there has been tremendous technical progress over the last ten years regarding solar farm stations as well as horizontal-axis wind turbines.

\section{2. - Physical basics}

$2 \cdot 1$. Energy content of the wind. - The following section will be used to mathematically explain where the energy in the wind comes from and what factors it depends on.

Power is defined as

$$
P=\frac{E}{t}=\frac{1}{2} \cdot A \cdot \rho_{a} \cdot v^{3}
$$

with $E$ : kinetic energy, $A$ : area, $\rho_{a}$ : specific density of the air, $v$ : wind velocity.

Therefore, it is also proportional to the cube of the wind speed, $v^{3}$.

From fig. 2, it can be seen that the power output per $\mathrm{m}^{2}$ of the rotor blade is not linearly proportional to the wind velocity, as proven in the theory above. This means that it is more profitable to place a wind turbine in a location with occasional high winds, than in a location where there is a constant low wind speed. Measurement at different places shows that the distribution of wind velocity over the year could be approximated by a Weibull-equitation. That means that at least about $2 / 3$ of the produced electricity will be earned by the upper third of wind velocity.

From a mechanical point of view, the power density range increases by one thousand for a wind speed change of just $10 \mathrm{~m} / \mathrm{s}$, thus producing a construction limit problem. 


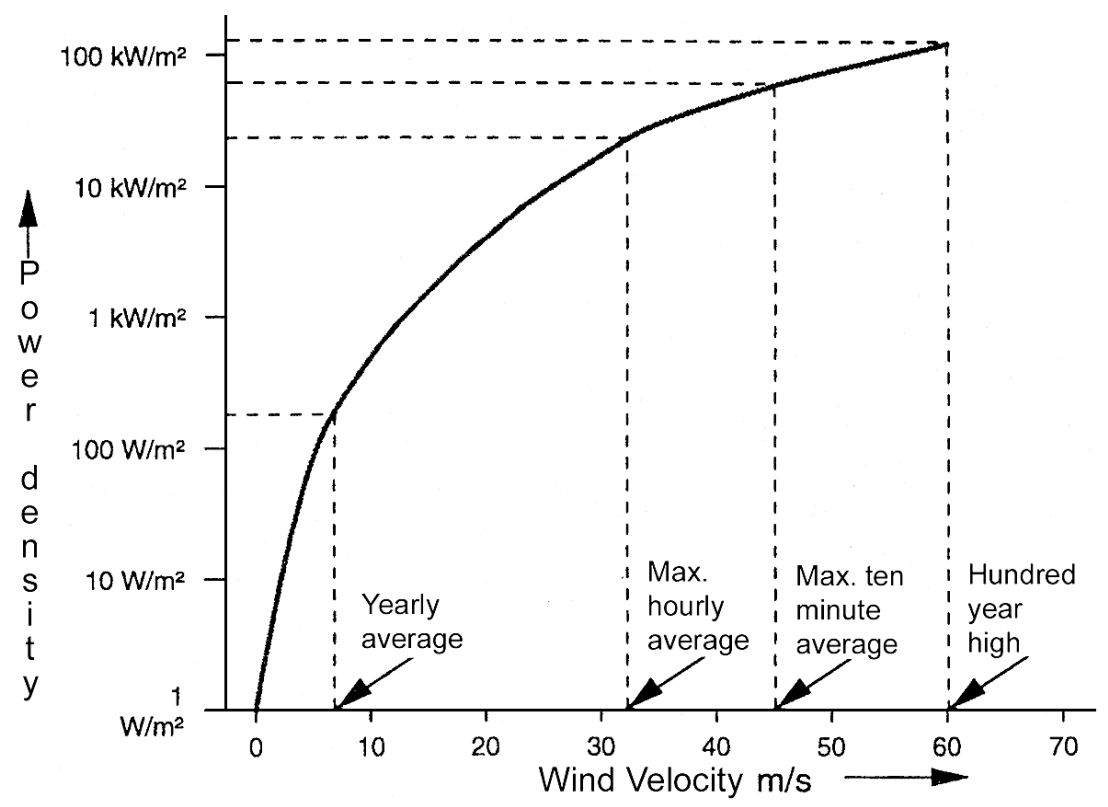

Fig. 2. - Relationship between wind velocity and power output (yearly average valid for Germany) $\left({ }^{1}\right)$.

Therefore, wind turbines are constructed to harness only the power from wind speeds in the upper regions.

$\mathbf{2} \cdot 2$. Power coefficients. - There is now the question of how much of the energy in the wind can be transferred to the blade as mechanical energy.

\section{Betz's law and $c_{p}$}

Betz's law states that you can only convert a maximum of $59 \%$ of the kinetic energy in the wind to mechanical energy using a wind turbine. This is because the wind on the back side of the rotor must have a high enough velocity to move away and allow more wind through the plane of the rotor.

The relationship between the power of the rotor blade $P_{R}$ and the maximum power $P_{R \max }$ is given by the power coefficient $c_{p}$;

$$
P_{R}=P_{1}-P_{2}=c_{p} \cdot P_{R \max }
$$

The maximum power coefficient is determined through the ratio $v_{2} / v_{1}$ and setting the

$\left({ }^{1}\right)$ This figure is taken from [1]. 
derivation to zero.

$$
c_{p \max }=\frac{16}{17}=0.593 \quad \text { with } \quad v_{2}=\frac{1}{3} \cdot v_{1} .
$$

Therefore, an ideal turbine will slow down the wind by $2 / 3$ of its original speed (Betz's law).

The issues discussed in the theory can be summed up and related to the design of a wind energy turbine, by the so called Cooking recipe:

"Cooking recipe" for the design of wind turbines.

1. A high aerofoil form ratio leads to a high Tip-speed ratio and therefore, a large power coefficient $c_{p}$.

$\Rightarrow$ Modern turbines with a good aerodynamic profile rotate quickly.

2. Simple profiles with smaller profile form ratios have a small Tip-speed ratio. Therefore, the area of the rotor radius that is occupied by blades must be increased in order to increase the power coefficient.

$\Rightarrow$ Slow rotating turbines have poor aerodynamic profiles and a high number of blades.

3. The profile form ratio and the tip-speed ratio have a considerably greater influence on the power coefficient than the number of blades.

$\Rightarrow$ The quality of an aerofoil in respect to a high speed turbine has an inferior significance.

\section{3. - Technical design of wind turbines}

3`1. The design with gearbox. - The details of a design with gearbox are shown in fig. 3. The main aspect of the classic design is the split shaft system, where the main shaft turns slowly with the rotor blades and the torque is transmitted through a gearbox to the high-speed secondary shaft that drives the few-pole pair generator.

The transmission of torque to the generator is shut off by means of a large disk brake on the main shaft. A mechanical system controls the pitch of the blades, so pitch control can also be used to stop the operation of the turbine in e.g. storm conditions. The pitch mechanism is driven by a hydraulic system, with oil as the popular medium. This system needs almost yearly maintenance and constant pressure monitoring, along with the gear box which is lubricated with oil. Due to mechanical losses in the gearbox, the oil will be treated and must be cooled. For constructions without a main brake, each blade has its pitch angle controlled by a small electric motor. This is the standard by most all wind converters. 


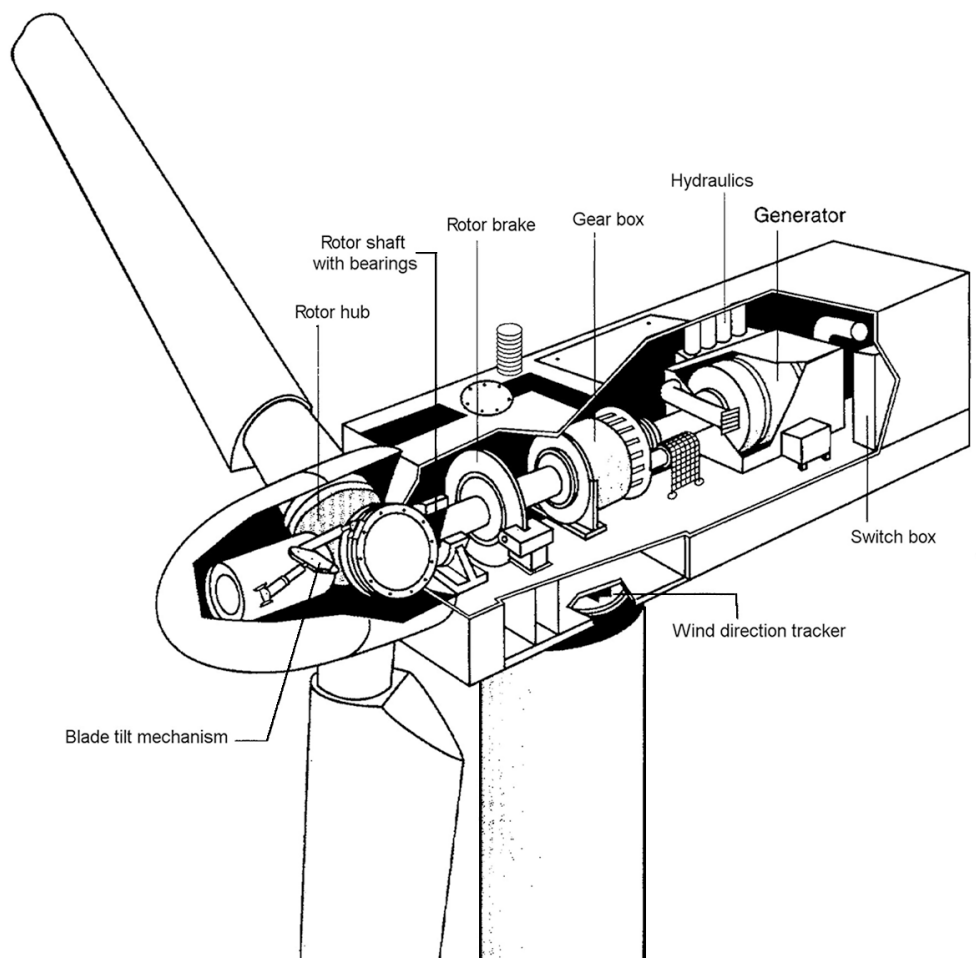

Fig. 3. - The design with gearbox.

To reduce weight generators with permanent magnets was developed. Some producers are equipping their converters with it last years.

In order to reduce vibrations by high speeds in the rotating axe, generators are often designed with more that one pole pair. This allows a reduction in the rotation velocities between the gear box and the generator. The problem with this type of configurations is that the size and weight of the generator increases with the number of pole pairs.

Wind speed and direction measuring apparatus are located at the back of the hub head. A rack-and-pinion mechanism at the join of the hub and the tower, allows the hub to be rotated in to the wind direction, and out of it in storm conditions.

3·2. The design without gearbox. - Some companies e.g. the German company Enercon, design another turbine type, without gearbox. The scheme of such a turbine is shown in fig. 4, where the main design aspects can be clearly seen.

This design has just one stationary shaft. The rotor blades and the generator are both mounted on this shaft. The generator is in the form of a large spoked wheel with e.g. forty-two pole pairs, around the outer circumference and stators mounted on a stationary arm around the wheel. The wheel is fixed to the blade apparatus, so it rotates slowly with the blades. Therefore, there is no need for a gearbox, rotating shafts or a disk brake. This 


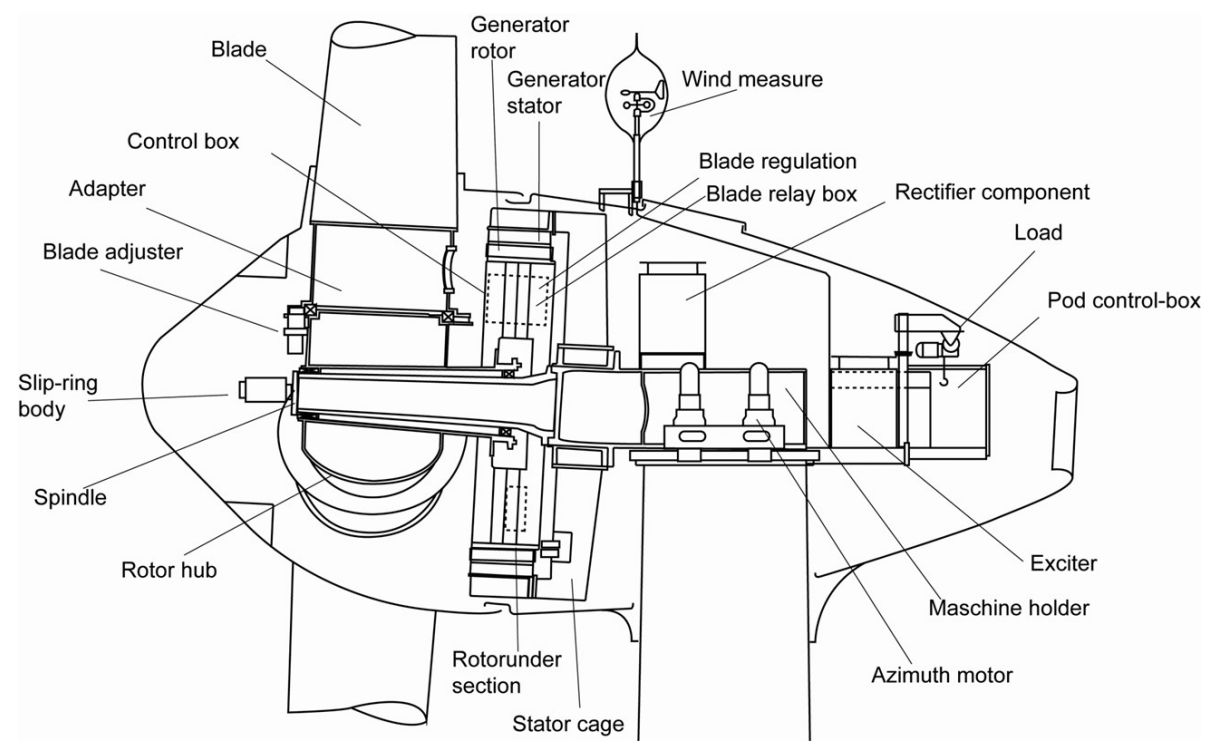

Fig. 4. - The design without gearbox (Enercon E-66).

minimising of mechanical parts simplifies the maintenance and production of the turbine.

The whole system is automated; pitch control and hub direction are controlled by a central computer, which operates the small directional motors.

3.3. Aspects of design and development. - There are several critical aspects of a wind turbine that need to be considered in the design phase, to ensure the turbine will be economic and durable.

\section{The tower}

In principle, the tower needs to be as tall as possible, because the wind speed increases with height. However, the height is limited by costing issues; an increase in tower height of $10 \mathrm{~m}$ costs an extra fifteen thousand Dollars, and a tower height of over $100 \mathrm{~m}$ requires an aircraft-warning beacon, which is again so expensive.

\section{Heat energy}

Large turbines (> $1 \mathrm{MW}$ ), have an average generator efficiency of $98 \%$. Heat is also generated in the mechanical parts of the machine including the bearings and the gear box. This means that around $40 \mathrm{~kW}$ of power are lost to the generator heating up during operation. This heat energy needs to be controlled to prevent damage to the machine parts. A large fan system is mounted in on the back side of the hub of a turbine and used to draw cool air through the hub and remove the heat energy emitted during operation. 


\section{Control and monitoring}

The following aspects of a wind turbine need to be controlled and monitored to ensure effective operation of a wind turbine within the legal limits:

- By large turbines; vibration levels.

- Speed of rotation and the pitch angle, of the rotor blades.

- The natural wind speed and direction.

- The voltage and frequency of the electricity produced.

- The output phase angle compared to the grid phase angle.

- The consistency of the electrical power output.

- The acquisition and storage of electrical signals.

- Signal conversion equipment for the directional motors.

- Rotational speed at night, to reduce the noise levels, because the noise is proportional to the blade-tip speed to the power six.

\section{Mechanical stability}

The following forces affect the stability of the mechanical system:

- Gravity.

- Centrifugal forces on the rotor blades.

- Pressure changes on the blade due to the shadow effect the tower creates.

- Stochastic power output of the turbine due to wind energy levels continually changing.

- Resonance of the blades.

\section{Wind direction set-up}

A wind turbine can be designed to face in to the wind (windward), or away from it (leeward). A leeward turbine has the advantage of being self orientating, but the disadvantage of the tower disturbing the wind velocity profile, before the wind has reached the plane of the rotor blades. The pressure and speed differences experienced by the blade as it passes the tower, result in stresses on the hub, which need to be alleviated by use of an extra mechanism in the hub to allow the rotor blades to move out of their usual plane of rotation. 
TABLE I. - The technical figures of two different multi-megawatt wind turbines for onshore.

\begin{tabular}{lcc}
\hline & Enercon E-182 E3 & REpower 3.2 MW \\
\hline Design & without gearbox & with gearbox \\
Hub height & $80-130 \mathrm{~m}$ (onshore) & $100-130 \mathrm{~m}$ (onshore) \\
No. of blades & 3 & 3 \\
Rotor speed & $6-18 \mathrm{rpm}$ & $6.7-12 \mathrm{rpm}$ \\
Rotor diameter & $82 \mathrm{~m}$ & $114 \mathrm{~m}$ \\
Material of blade & Fibreglass (reinforced epoxy) & Fibreglass (reinforced epoxy) \\
Blade regulation & Pitch & Pitch \\
Rated power & $3 \mathrm{MW}$ & $3.2 \mathrm{MW}$ \\
Transmission ratio of gearbox & None & approx. 99 \\
Generator & Multi-pole & Asynchronous, few poles \\
Grid connection & Via frequency converters & Via frequency converters \\
\hline
\end{tabular}

3.4. Technical figures of two modern wind turbines. - The largest market introduced machine up to the year 2014, is a $8 \mathrm{MW}$ turbine from the company Vestas.

Table I gives an idea of the technical data of wind turbines of the $3 \mathrm{MW}$ class. A design with and without gearbox have been chosen to show the different operation of their generators.

\section{4. - Connection to the electrical grid}

The main electrical grid has a constant frequency e.g. of $50 \mathrm{~Hz}$ or $60 \mathrm{~Hz}$ and a constant phase angle. Therefore, a wind turbine must produce electricity with the same constant values in order to be integrated into the main grid.

The input energy of a wind turbine is proportional to the wind speed, but the wind speed is never constant. Each wind speed has a corresponding rotor rotation speed, at which the maximum power is produced. This maximum occurs for different wind speeds at different rates of rotation. However, the rate of rotation must be held constant in order to achieve the required constant output frequency or the wind turbine has to be connected to the grid by doubly fed asynchronous generator or by electronic frequency converters.

A small turbine can be connected directly into the grid network at $0.4 \mathrm{kV}$. When the wind turbine is integrated into the grid network, there must be no voltage change, voltage oscillation or flicker experienced in the homes on that network branch. The loss of voltage due to resistance in the cabling can be avoided by increasing the diameter of the cables. It is often required that a new network branch is constructed and linked to the transformer, in order to reduce the voltage disturbances. This increases the installation costs of the turbine. 


\section{Percent of total capacity (28 MW)}

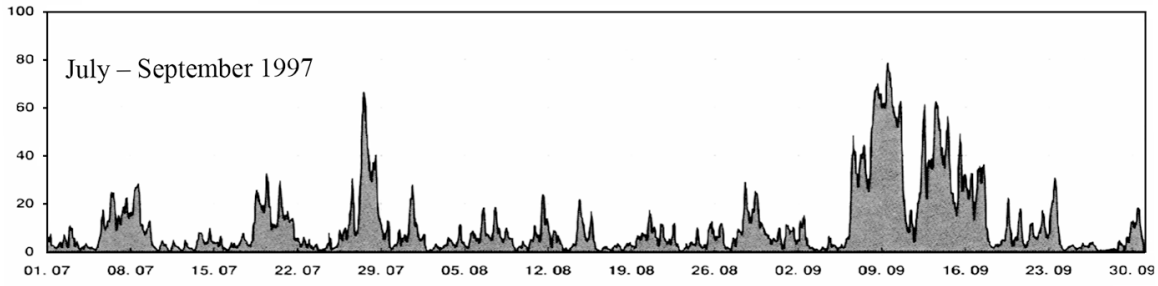

Percent of total capacity ( $28 \mathrm{MW})$

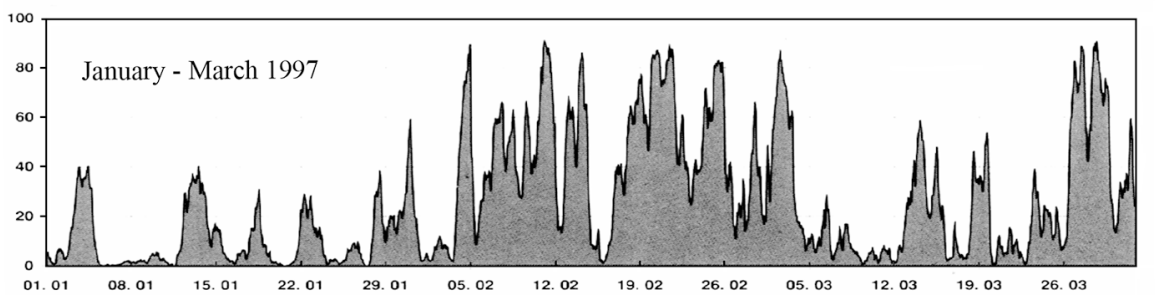

Fig. 5. - Load distribution measurement (Germany).

Megawatt turbines cannot be connected to the grid at the $0.4 \mathrm{kV}$ stage, but have to be connected in at $10-30 \mathrm{kV}$, which is the usual level of the city electricity share distribution. In remote areas, where a $30 \mathrm{kV}$ connection is not established, the connection must be created and financed by the wind park developers. Wind parks with a lot of Megawatt turbines can also be connected into the electrical grid e.g. at the $110 \mathrm{kV}$ level in Germany.

As mentioned earlier the maximum power output is obtained only in few hours during the year. Figure 5 shows a typical load distribution, measured in Germany. With larger wind energy installations in future this uneven distribution leads to the need of higher regulation capacities by conventional power systems.

Grid connection of offshore wind farms poses a technical and economical challenge to wind turbine and grid operators. In the initial phase, the still quite limited capacity of early pilot farms enables using a conventional three-phase $\mathrm{AC}$ connection to the onshore grid system which is a well-known technology and inexpensive. This wind farms were also located near to the coast, the energy losses by using AC was therefore limited.

Greater capacities and remote offshore sites make it technically difficult to connect offshore wind farms to the mainland grid by using AC undersea cables. Losses, reactive power production and limited capacity of the sea cables may become important in the future. High-voltage direct current transmission to land could be a solution but it is technically more complicated and more expensive.

At the moment there are some plans for connecting offshore wind farms to the mainland grid. Some lines, AC and DC operated, are already into operation, some more are under realising ore planning. To protect environment on sea several wind farms are connected to one line. 
TABLE II. - World wind power production $\left(^{2}\right)$.

\begin{tabular}{lc}
\hline Land/Region & Total installed rated power up to the end of $2015[\mathrm{GW}]$ \\
\hline China & 145 \\
USA & 74 \\
Germany & 45 \\
Spain & 23 \\
India & 25 \\
UK & 14 \\
Italy & 9 \\
France & 10 \\
Canada & 11 \\
Brazil & 9 \\
Remaining countries & 67 \\
\hline Total & 432 \\
\hline
\end{tabular}

To connect the offshore wind farm to the onshore grid an internal grid is necessary. The produced power has to be feed to an offshore transformer substation. Wind turbines are connected to it via undersea cables by a voltage of about $30 \mathrm{kV}$. After stepping-up to the transmission line voltage, the power is conveyed to shore.

\section{5. - Use of wind energy}

5`1. Worldwide status. - In the nineteen eighties, it was the USA that took the lead in establishing wind farms. They set over 10000 turbines into operation, each generating between $80-200 \mathrm{~kW}$. In Europe it was Denmark that was the main pioneers of wind energy. At the end of twenty-first century, Germany has taken the world lead, producing about a third of the world's wind produced electricity until 2008.

Many governments have began to produce incentive schemes to increase the economic feasibility of wind turbines. Some incentives used include both paying more for wind produced electricity and providing a proportion of the initial construction costs. Governments of industrial countries, or those with a high power consumption, are eager to promote wind energy, because it is environmentally clean and sustainable and limits the need for fossil fuel usage (table II).

The world total rated power was by the end of the year 2015 about $432 \mathrm{GW}$. This is about $1.8 \%$ of the worldwide installed capacity of power stations (water, coal, naturalgas, nuclear).

$\left({ }^{2}\right)$ This statistic is taken from [2]. 
TABLE III. - (a) The typical investment costs of a $2 \mathrm{MW}$ onshore wind power station in Germany (Amesdorf) (Status: 2013) $\left({ }^{3}\right)$. (b) The typical operating costs of a $2 \mathrm{MW}$ onshore wind power station in Germany (Wellen) (Status: 2013) $\left({ }^{3}\right)$.

(a)

\begin{tabular}{|l|l|c|}
\hline \multicolumn{1}{|c|}{ Investment plan } & \multicolumn{2}{|c|}{$\begin{array}{c}\text { Costs } \\
{[€ / \mathrm{kW}]}\end{array}$} \\
\hline \multicolumn{1}{|c|}{ Hub height } & $<120 \mathrm{~m}$ & $>120 \mathrm{~m}$ \\
\hline Wind power station, transport, installation & 1150 & 1340 \\
\hline Foundation & \multicolumn{2}{|c|}{70} \\
\hline Grid connection & \multicolumn{2}{|c|}{40} \\
\hline Site development (lanes) & \multicolumn{2}{|c|}{190} \\
\hline Planning, environmental measures, concession, others & 1520 & 1710 \\
\hline \hline Total & \multicolumn{2}{|c|}{} \\
\hline
\end{tabular}

(b)

\begin{tabular}{|l|c|}
\hline \multicolumn{2}{|c|}{$\begin{array}{l}\text { Operating costs: } 5.1 \mathrm{ct} / \mathrm{kWh} \\
\text { (Average over 20 years operating time) }\end{array}$} \\
\hline Service, reparation, others & $50 \%$ \\
\hline Rent & $20 \%$ \\
\hline Management (technical and business) & $20 \%$ \\
\hline Reserve for unforeseen events & $5 \%$ \\
\hline Insurance & $5 \%$ \\
\hline
\end{tabular}

It should be taken into account that wind energy have a lower capacity factor than fossil and nuclear power stations (around 1) with around 0.3 to 0.4 for onshore wind power and around 0.5 for offshore wind power.

5·2. Offshore wind status. - Due to high wind potential at Germany's coastline, wind energy should play a decisive role. Therefore, Germany's government plans to install around 6.5 GW of offshore wind parks until 2020 and $15 \mathrm{GW}$ until 2030. By the end of the year 2015, the wind power installed capacity in Germany for offshore was around $3.4 \mathrm{GW}$ and for onshore around $42 \mathrm{GW}[3]$.

5.3. Investment and operation costs. - The costs involved in installing a wind turbine vary depending on the design, size and chosen location of the new turbine. The infrastructure costs can be minimised by constructing wind parks, where a number of new turbines are installed on the same sight. An example of the investment costs for a wind park at land in Germany is shown in tables III(a) and III(b).

The money invested in an average wind park on land depreciates over about a ten year period. During this period, the set-up and installation costs are high, along with the

$\left(^{3}\right)$ These data are taken from WindGuard GmbH, Germany. 
loan repayments and insurance costs. After this period, the costs then decrease. Over the next ten years, a financial return can then be made on the investment, when the price for the electricity per kilowatt hour is set at a high value by the government. This means it is economic to ensure the durability of the installed turbines, so maintenance costs after the ten year period are kept low and the investors can receive a good return on their investment.

The above example of investment costs for wind parks on land in Germany is nontransferable to other countries. Especially the employee's wages and the structure of financing wind farms are quite different. Nevertheless power generating by wind turbines in developed countries with existing electrical grid and sufficient installed power, costs three to four times in comparison to power generation by conventional power stations.

Wind parks on sea need higher specific investments, although the wind offer is better on sea than on land. The costs of produced electricity are higher by an offshore wind park (status 2012). The expectation is that the cost could be reducing for new offshore wind parks in next years. A lot of countries are supporting the installation of wind converters by supporting programs.

5•4. Environmental aspects. - Wind energy is a renewable energy source; therefore it holds many advantages over the fossil fuels, which have diminishing reserves. Wind energy is clean in regard to toxic emissions. Therefore, it does not add to Global warming or Acid rain problems.

The wind turbines can affect the environment in aesthetic and human intrusive ways. This is because they must be sited in prominent locations and through the nature the rotation of their blades; they produce optical distortions, i.e. flickering shadows, and a humming noise. The land required for the sighting of a wind park can be considered large, if all the access routes are also taken into consideration. However, they very rarely require the resettlement of communities, which is a problem associated with e.g. large Hydro-Electric-Power stations. The danger to birds of the rotating blades has been questioned, but it has been found that the birds change their flight paths to avoid the blades. It has also be questioned whether the reduced wind speed at ground level, affects the growth of flora. This is answered by the observation that many wind parks have animals grazing between the turbines.

55. Life cycle analysis. - Life Cycle Assessments (LCA) is an important tool for industry and policy makers, used to determine the actual emissions of a product or technology throughout its whole life cycle. In case of energy production systems or power plants, analysis of energy required to produce the materials and processes; emissions resulting from various processes for materials production and processes resulting into their Cumulated Energy Demand (CED) and Global Warming Potential (GWP) become important parameters when making decisions on further research, development and deployment of any technology. Results and characteristics of wind energy LCA were for the first time analyzed in the German offshore wind farm alpha ventus. Alpha ventus is a test field in the North Sea for $5 \mathrm{MW}$ wind energy converters in a water depth of $30 \mathrm{~m}$. 
Results shown that within less than one year the energetic expenditure as well as the greenhouse gas emission of the entire life cycle of alpha ventus is amortized [4].

\section{6. - Research and development needs}

The field of wind converter has been connected with high technical development activities for many years. The first report of the project "Wind Energy Thematic Network" [4] founded by the European Commission described in the year 2012 some aspects, which are also relevant in:

1. Environmental and social impacts (e.g. enhancing local incentives by developing participation models):

- methods to integrate wind turbines visually in to the landscape,

- reduction of noise impacts,

- mitigating impacts on bird populations, habitats and flight paths,

- turbine design regarding life cycle analysis,

- analyse social effects like local employment, investment, taxes etc.

2. Wind turbine and component design issues (e.g. basic research in aerodynamics, structural dynamics, structural design and control):

- new materials with higher strength like carbon fibre for the blades,

- feasibility studies of new wind turbines concepts and innovations,

- integration of demand site requirements in the design of turbine, e.g. electrical control system interaction with grid requirement.

3. Testing, standardisation, and certification (e.g. common accepted certification procedures for wind turbines and wind farms):

- identification of standards lacking, and initiation of appropriate actions for new standards,

- standards for service and maintenance concepts of offshore wind converters.

4. Grid integration, energy systems and resource prediction (e.g. forecast of wind resource):

- development of scenarios for redesigning the grid system with high wind penetration,

- increasing both: power quality and consistency,

- energy management and storage systems for stand alone applications.

5. Operation and maintenance (e.g. advanced condition monitoring):

- development of early failure detection and condition systems,

- development in preventative maintenance, 
TABLE IV. - Technical developments in Wind Turbines [5].

\begin{tabular}{l|l}
\hline \multirow{3}{*}{ Generators } & - Copper? Permanent Magnet? \\
& - Rare earths? \\
& - Superconductors? \\
\hline \multirow{3}{*}{ Rotor Blades } & - Cost reduction? \\
& - Utilization? \\
& - Legal situation? \\
& - Active control elements in rotor blades? \\
\hline \multirow{3}{*}{ Operations Monitoring } & - Drive train monitoring (CMS) for onshore plants? \\
& - Tower- and foundations vibrations - Number of Sensors, \\
& also Onshore? \\
\hline Technical Uncertainties & - Periodic Inspections- Scope, Number? \\
\hline \multirow{3}{*}{ Offshore Foundations } & - Handling of new developments? \\
\hline technologies & - Gravity Foundations? \\
& - Environment, under water noise protection during the piling \\
& for the foundation? \\
\hline
\end{tabular}

- standardisation of components for easy replacement,

- certification of service and maintenance concepts,

- cold and icing climates resource assessment.

6. Offshore wind technology (e.g. research into the control and efficiency of very large wind farms and more cost effective foundations, transport and installation techniques):

- monitoring of environmental impacts (effects on birds, effects of noise and vibration on marine life especially by installation of wind converter etc.),

- development of deep water foundation structures (fundamental wind turbine design research),

- offshore meteorology,

- special designs of systems and components for transportation, erection, access and maintenance of offshore wind turbines,

- investigate the use of energy storage,

- improve corrosion protecting systems regarding the offshore conditions.

In addition to these aspects there have been done a lot of $\mathrm{R} \& \mathrm{D}$ needs by operating and market introduced wind turbines, e.g.:

- better state of knowledge of the dynamic forces on the drive train,

- improvement of the availability of gear boxes, 
- optimisation of control units and control systems,

- development of central lubrication systems.

From a technical perspective several configurations for wind technologies are under research and development in Germany (table IV).

\section{7. - Outlook}

The wind energy market has grown because of the environmental advantages of harnessing a clean and unexhaustable energy source and because of the economic incentives supplied by several governments. However, energy is required from other generation methods during the building phase of a new turbine, so in this period, Greenhouse gases and air pollution will be added to. If the life cycle of a wind turbine is looked at, more pollutants are saved on during operation, than are emitted during the building phase.

A wind turbine is not a self-sustainable power station. This means that back-up power generation is needed at the times when the turbine is inoperative. This back-up is nowadays supplied by the established fossil fuel power stations. If the number of wind turbines increases, the need for extra investment in the back-up generation systems will rise, in order to maintain a stable electricity grid system. The challenges in this case are that existing power stations will deliver less electricity than before. Under this condition the electricity generation prices for new power stations are increasing due to smaller load duration time than before.

However, wind energy is still one of the most important renewable energy resources for the future, because it can be harnessed in a clean and inexhaustible manner, through the application of technically advanced and efficient machinery. These additional investments will need in some cases subsidies. For more information especially in respects to technological and ecological aspects (life cycle aspects) see [4].

\section{REFERENCES}

[1] Kleemann M. and Meliß M., Regenerative Energiequellen, 2.Auflage (Springer-Verlag, Heidelberg) 1993.

[2] www.GWEC.de.

[3] Ender C., "Wind Energy Use in Germany", DEWI Magazin 02/2016.

[4] Wagner H.-J. and Mathur J., Introduction to Wind Energy Systems - Basics, Technology and Operation, second edition (Springer-Verlag, Berlin) 2013, ISBN 978-3-642-32975-3.

[5] Wagner Hermann-Josef, "Erneuerbare Energien Wind und Sonne - Wo geht es technisch hin?", VGB PowerTech 1/2, 2015. 